\title{
Effect of Inner Step Length on the Stress Distribution in Weld-bonded Single Lap Aluminum Joint
}

\author{
Jian-Li LI ${ }^{1, a}$, Peng WANG ${ }^{2, b}$ and Min YOU ${ }^{1,3, c,{ }^{*}}$ \\ 1 Hubei Three Gorges Polytechnic, Yichang 443000, China
}

\author{
2 Wuhan Tower Works, Power Construction Corporation of china, Wuhan 430011, China \\ 3 Hubei Key Laboratory of Hydroelectric Machinery Design \& Maintenance, China Three Gorges \\ University, Yichang 443002, China \\ a lj|@tgc.edu.cn, b597013645@qq.com.com, cyoumin@ctgu.edu.cn
}

${ }^{*}$ Corresponding author

Key words: Weld-bonded joint, Aluminum alloy, Inner step length, Stress distribution, FEA

\begin{abstract}
The numerical analysis of the inner step length on the stress distribution in weld-bonded single aluminum lap joint was investigated using elasto-plastic finite element method (FEM). The results from the numerical simulation show that the peak stress along the bondline peak stress at the end of lap zone is decreased when the inner steps were arranged in the adherend and it is decreased as the step length increased. Compared to the results from the normal joint, appropriate inner step length is beneficial to optimize the stress distribution in single-lap aluminum weld-bonded joint.
\end{abstract}

\section{Introduction}

The chamfering or tapering method for the adherend to uniform the stress distribution in adhesively bonded single lap joints was studied by some researchers [1-4]. It was reported by Belingardi et al [1] that the magnitude of the stress peaks (for both shear and peeling components) decreased in entity with the decrease of the inner chamfer angle. Sancaktare and Nirantar [2] founded that the lower peak normal shear stresses along the adhesive-adherend interface, the smaller taper angle. Vallee et al [3] discussed the factors in the stress-reduction methods on the strength of adhesively bonded joints. The numerical and experimental study of the effect of the inner chamfer on the stress distribution in the adhesively bonded aluminum single lap joints was carried out by the authors [4]. And the effect of elastic modulus of the adhesive [5] as well as the outer chamfer in the adherends [6] on the stress distribution in the weld-bonded aluminum single lap joints was investigated in recent years. The aim of this work is to study the effect of inner step length on the stress distribution in the weld-bonded single lap aluminum joint.

\section{Finite Element Model and Mesh}

The model and mesh were built using the ANSYS finite element software as shown in Fig.1 and Fig.2. The properties of the materials used in this study considered the non-linear behavior, bilinear isotropic hardening plasticity option (BISO) to describe the elastic-plastic behavior of material are listed in Table 1. The load applied was taken as $2 \mathrm{kN}$ and the dimensions of the aluminum adherend were made in accordance with the Chinese standard GB 7124 (equivalent to ISO 4587). The triangular element was used for both bondline and the nugget and quadrilateral element for adherend (Fig.2). The thickness of the bondline was $0.2 \mathrm{~mm}$ and divided into 10 layers. To investigate the effect of the inner step length thoroughly, five step length were taken into account as $4 \mathrm{~mm}, 3 \mathrm{~mm}, 2 \mathrm{~mm}$, $1 \mathrm{~mm}$ as well as 0 (standard joint) respectively and the height of step was kept as $0.5 \mathrm{~mm}$. The nugget was assumed in a shape of ellipsoid. 
Table 1 Mechanical Properties of the Materials

\begin{tabular}{ccccc}
\hline Materials & $\begin{array}{c}\text { Elastic Modulus } \\
(\mathrm{GPa})\end{array}$ & $\begin{array}{c}\text { Poisson's } \\
\text { Ratio }\end{array}$ & $\begin{array}{c}\text { Yield Strength } \\
(\mathrm{MPa})\end{array}$ & $\begin{array}{c}\text { Tang Modulus } \\
(\mathrm{MPa})\end{array}$ \\
\hline $\begin{array}{c}\text { Aluminum alloy } \\
\text { LY12 }\end{array}$ & 71 & 0.32 & 400 & 240 \\
\hline $\begin{array}{c}\text { Nugget } \\
\begin{array}{c}\text { Phenolic resin } \\
\text { adhesive }\end{array}\end{array}$ & 102 & 0.29 & 800 & 210 \\
\hline
\end{tabular}

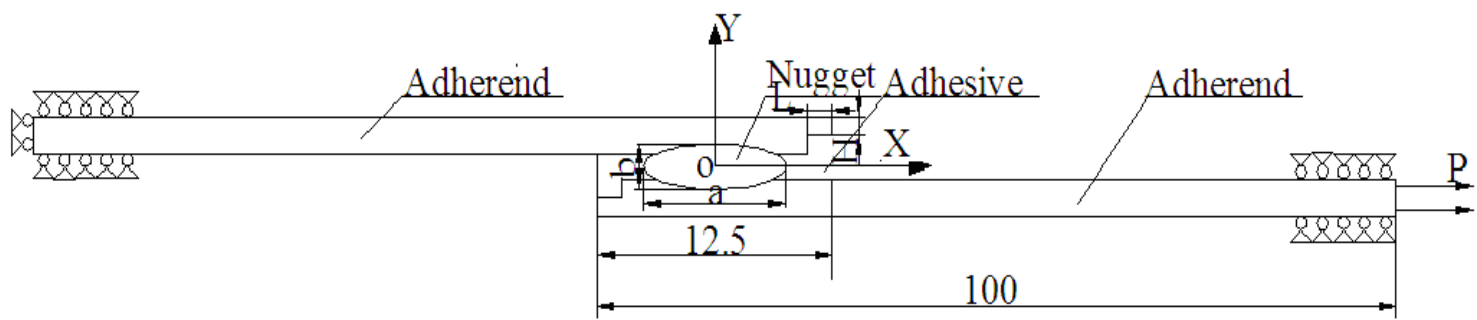

Fig.1 Finite element model (unit: $\mathrm{mm}$ )

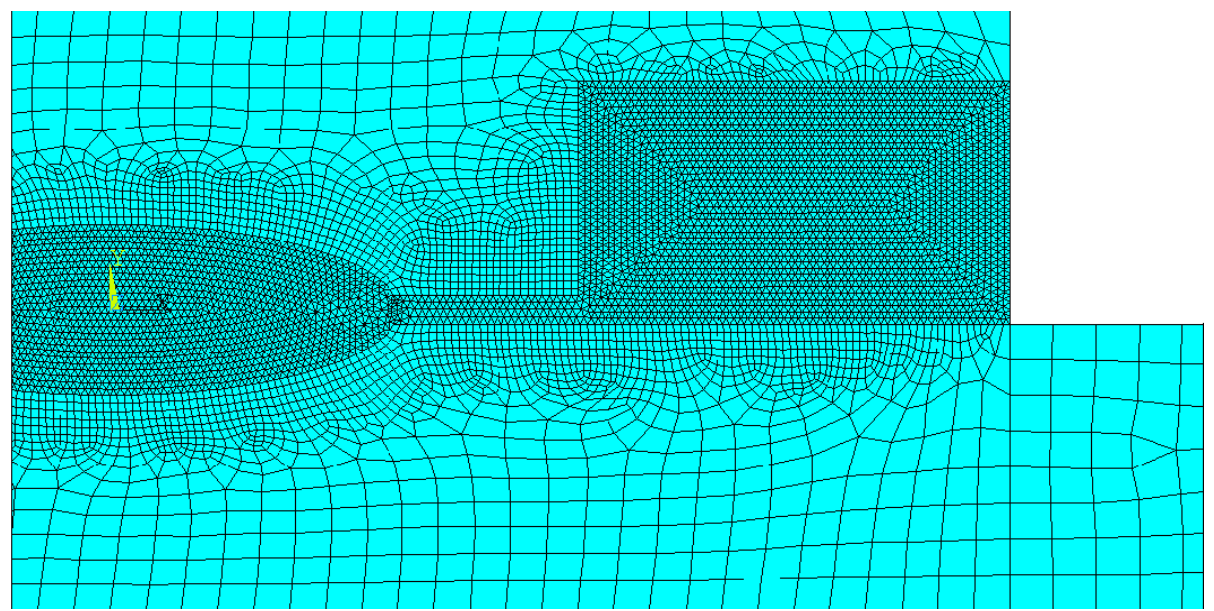

Fig.2 Finite-element meshes for right half of over lap zone.

\section{Results and Discussion}

The effect of the step length on the stress distribution along $\mathrm{x}$ axis $(\mathrm{y}=0)$ is presented in Fig.3. The results from the simulation showed that the peak values of the stress components $S x, S y, S x y$ and the von Mises equivalent stress $S e q v$ are evidently affected by the inner step length (Fig. 3). For the peak value of the stress $S x, S y, S x y$ and $S e q v$ occurred at the points near both ends of the over lap zone in the joint, it is decreased significant as the step length increased when it is not greater than $2 \mathrm{~mm}$. For instance, the peak value of stress longitudinal $S x$ is decreased $29.3 \%$ from 10.3 MPa to 7.28 MPa when the step length decreased from 0 to $2 \mathrm{~mm}$ (Fig. 3a) and then increased to $7.66 \mathrm{MPa}$ as the length reached $4 \mathrm{~mm}$. For the von Mises equivalent stress Seqv, the decrease of peak stress is $45.6 \%$ from about $37.7 \mathrm{MPa}(\mathrm{L}=0)$ to $20.9 \mathrm{MPa}(\mathrm{L}=2 \mathrm{~mm}$, Fig. 3d). Compared the results obtained with what reported in Ref. [5], the effect of the $2 \mathrm{~mm}$ inner step length for the longitudinal stress $S x$ is similar to use the lower modulus adhesives on the weld-bonded aluminum single lap joint. But to the stress $S x$ occurred in the nugget, it is clearly that the peak stress increased evidently as the step length increased (Fig. 3a). Higher peak stress in the nugget means that more load could be carried out by the nugget so that the load bearing capacity of the joint may be raised. The stress distribution tendency along the mid-bond line of the shear stress $S x y$ and the von Mises equivalent stress Seqv is 
similar to that of the longitudinal stress $S x$ and peel stress $S y$ in which the value of the peak stress is increased and moved to the middle part of the over lap zone when the step length increased. In Fig $3 b$, the value of stress $S y$ at end of lap zone is decreased and then increased when the length is greater than $1 \mathrm{~mm}$ but the peak value of stress $S y$ in mid-bondline decreased evidently as the step length increased such as $26 \mathrm{MPa}(\mathrm{L}=0), 14.8 \mathrm{MPa}(\mathrm{L}=1 \mathrm{~mm}), 8.82 \mathrm{MPa}(\mathrm{L}=2 \mathrm{~mm}), 5.47 \mathrm{MPa}(\mathrm{L}=3 \mathrm{~mm})$ and $3.76 \mathrm{MPa}(\mathrm{L}=4 \mathrm{~mm})$ respectively. And the absolute value of the peel stress $S y$ in the nugget is increased as the step length increased.
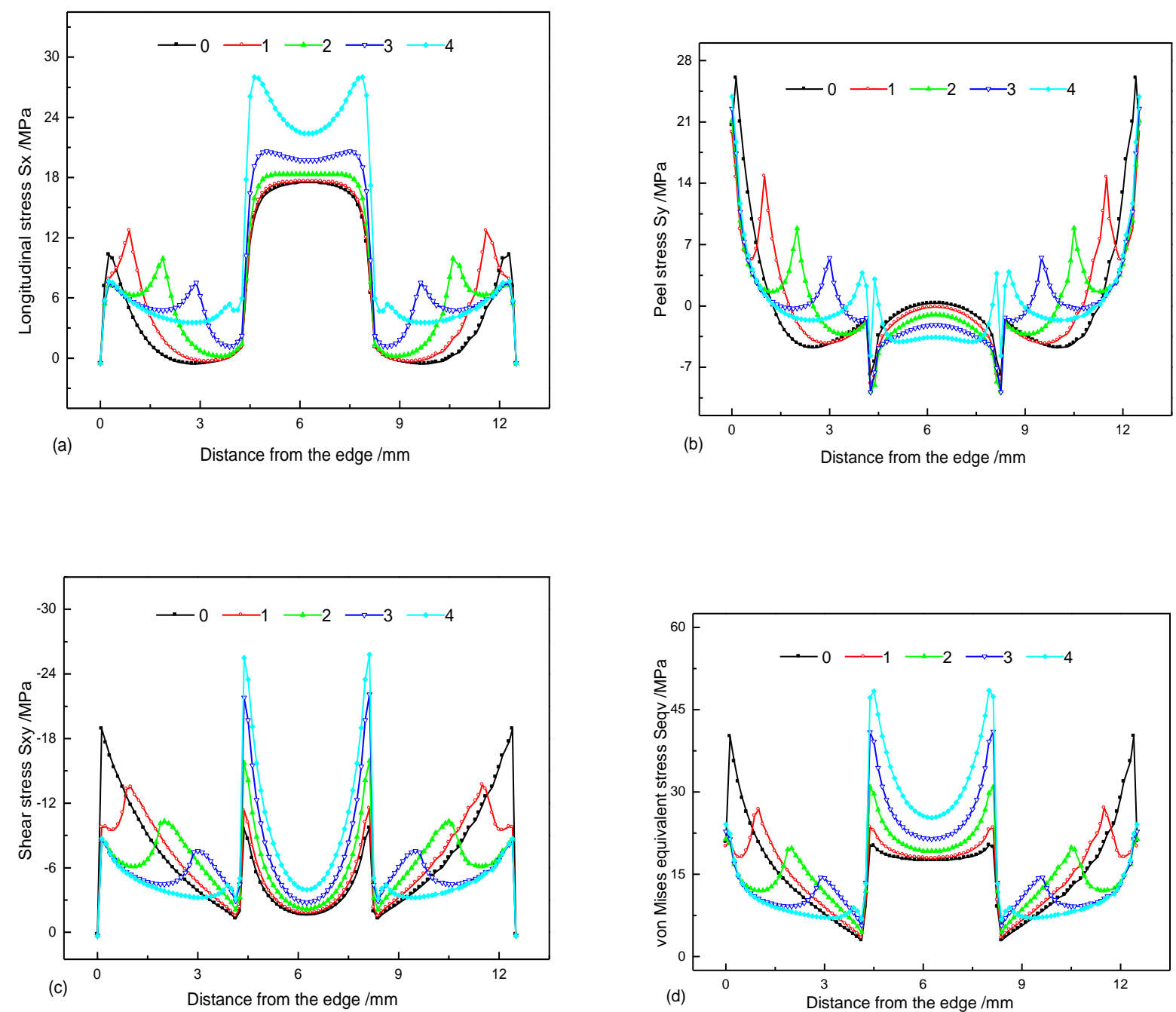

Fig.3 Effect of the step length on the stress distribution along the mid-bondline:

(a) longitudinal stress Sx; (b) peel stress Sy; (c) shear stress Sxy and (d) von Mises equivalent stress Seqv

When the conditions kept as the same, the effect of the step length on the stress distributed in the adherend near the interface $(y=-0.15 \mathrm{~mm})$ is shown in Fig.4. The results from the finite element analysis showed that the peak value of the stress $S x$ in the left half of the lap zone is decreased as the step length is greater than $1 \mathrm{~mm}$ (Fig. 4a). In same region, the varied tendency of the peak values for the shear stress $S x y$ and the von Mises equivalent stress Seqv (Fig. 4c and 4d) are similar to that of the stress $S x$. For stress $S y$, the absolute value of the stress near the center of the overlap zone is increased with the increase of step length (Fig. 4b). 

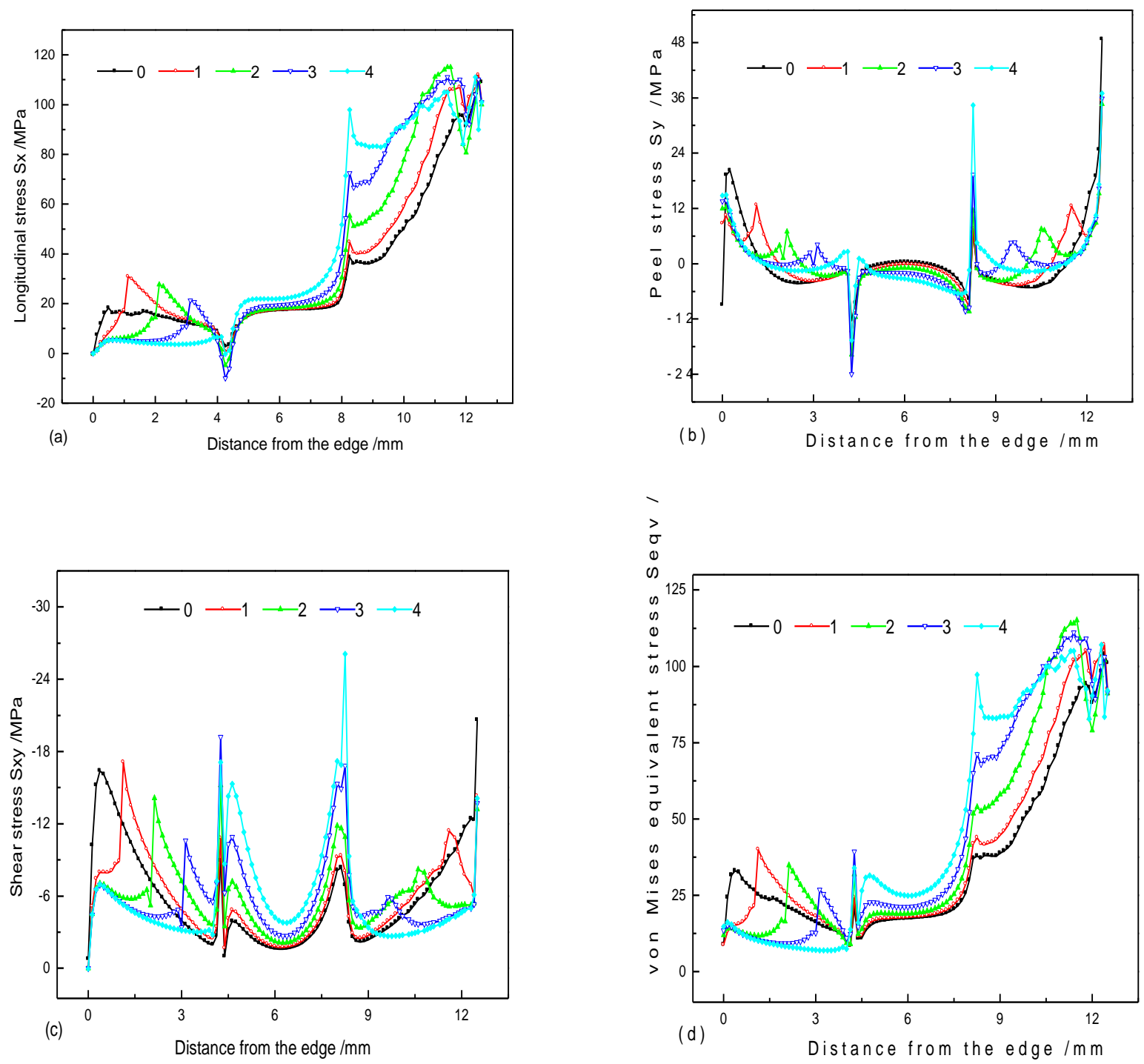

Fig.4 Effect of the step length on the stress distribution in adherend near the interface:

(a) longitudinal stress Sx; (b) peel stress Sy; (c) shear stress Sxy and (d) von Mises equivalent stress Seqv.

\section{Summary}

The results show that the peak values of the stresses along the mid-bondline is decreased for longitudinal stress $S x$ and peel stress $S y$ but increased for shear stress $S x y$ and von Mises equivalent stress Seqv as the step length increased. Compared to the joint with the standard one, it is advantageous of reducing the peak stress near the both ends of the lap zone in weld-bonded single lap aluminum joints. The results also show that the peak value of the stress $S x$ in the left half of the lap zone is decreased as the step length is greater than $1 \mathrm{~mm}$. Under the research conditions, the suitable inner step length is 2 to $3 \mathrm{~mm}$ for weld-bonded single lap aluminum joint.

\section{Acknowledge ments}

The authors would like to acknowledge the financial supported by the Hubei Province Natural Science Foundation of China under project no. 2014CFA123. 


\section{References}

[1] G. Belingardi, L. Goglio and A. Tarditi, Investigating the effect of spew and chamfer size on the stresses in metal/plastics adhesive joints, Int. J. Adhes. Adhes., 22(2002) 273-282.

[2] E. Sancaktare and P. Nirantar, Increasing strength of single lap joints of metal adherends by taper minimization, J. Adhes. Sci. Technol., 17 (2003) 655-675.

[3] T. Vallee, T. Tannert, J. Murcia-Delso, et al, Influence of stress-reduction methods on the strength of adhesively bonded joints composed of orthotropic brittle adherends, Int. J Adhes. Adhes., 30 (2010) 583-590.

[4] M. You, Z.-M. Yan, X.-L. Zheng, et al, A numerical and experimental study of adhesively bonded aluminium single lap joints with an inner chamfer on the adherends, Int. J Adhes Adhe, 28 (2008) 71

[5] M. You, J. -L. Yan, X.- L. Zheng, et al, Effect of elastic modulus of adhesives on stress distribution in weld-bonded joints, J. Aeronautical Materials, 29 (n3, 2009) 98-101(In Chinese).

[6] M. You, J. -L. Li, P. Wang and Y. -L. Zhao, Effect of the chamfer angle on the stress distribution in weld-boded single lap aluminum joint. Adv. Mater. Res., 1061(2015) 450-453 